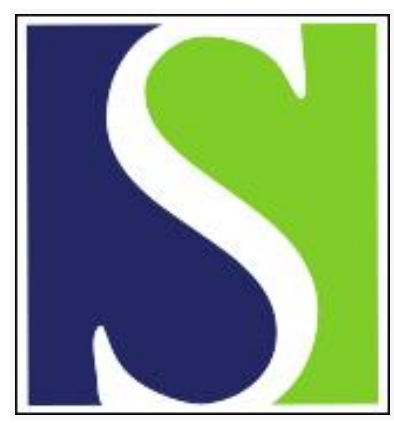

Scand J Work Environ Health 2014;40(4):353-360

https://doi.org/10.5271/sjweh.3411

Published online: 18 Dec 2013, Issue date: 01 Jul 2014

The contribution of major diagnostic causes to socioeconomic differences in disability retirement

by Polvinen A, Laaksonen M, Gould R, Lahelma E, Martikainen P

This study investigated socioeconomic differences in disability retirement due to major diseases using large register data. Socioeconomic differences in disability retirement were evident in all diagnostic groups, except depression in the older age group. Musculoskeletal disease was the largest contributing factor to the differences. Prevention, treatment, and rehabilitation of musculoskeletal diseases would likely reduce socioeconomic differences in disability retirement.

Affiliation: Finnish Centre for Pensions, 00065 Eläketurvakeskus, Finland. anu.polvinen@etk.fi]

Refers to the following texts of the Journal: $2011 ; 37(6): 464-472$ 2013;39(4):343-350

The following articles refer to this text: 2014;40(4):331-333;

2015;41(4):325-327; 2017;43(5):426-435

Key terms: depression; diagnosis; disability pension; disability retirement; excess disability retirement; mental disorder; mental illness; musculoskeletal disease; musculoskeletal disorder; socioeconomic difference; socioeconomic status

This article in PubMed: www.ncbi.nlm.nih.gov/pubmed/24352164

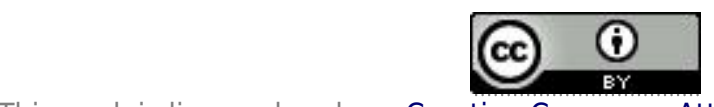




\title{
The contribution of major diagnostic causes to socioeconomic differences in disability retirement
}

\author{
by Anu Polvinen, MSocSc, ${ }^{1}$ Mikko Laaksonen, PhD, ${ }^{1}$ Raija Gould, LSocSc, ${ }^{1}$ Eero Lahelma, PhD, ${ }^{2}$ Pekka \\ Martikainen, $P h D^{3}$
}

\begin{abstract}
Polvinen A, Laaksonen M, Gould R, Lahelma E, Martikainen P. The contribution of major diagnostic causes to socioeconomic differences in disability retirement. Scand J Work Environ Health. 2014;40(4):353-360. doi:10.5271/sjweh.3411
\end{abstract}

\begin{abstract}
Objectives The aim of this study was twofold: to investigate socioeconomic differences in disability retirement (DR) due to major diseases and find out which diseases contribute most to the overall socioeconomic differences in DR.

Methods The data were longitudinal register-based (10\% sample of Finns) from Statistics Finland. These data included 258428 participants aged 35-64 years during the follow-up. The participants were employed or unemployed before the follow-up period 1997-2010. Of all participants, 14303 men and 13188 women ended up in DR during the follow-up. Socioeconomic status was categorized into upper- and lower-class non-manual employees, manual workers, and self-employed persons. Cox models were used to estimate hazard ratios for DR due to different diseases.

Results Compared to upper-class non-manual employees, DR was especially high for manual workers whose retirement diagnoses included psychoactive substance use, musculoskeletal diseases (MSD), or cardiovascular diseases. Socioeconomic differences in DR were stronger for younger age groups and men versus women. For females and males, the largest part of the excess DR among manual workers compared to upper-class non-manual employees was due to MSD. In the age group 54-64 years, the contribution of MSD to the total excess was $>50 \%$ among male manual workers and $75 \%$ among female manual workers. Excess DR due to mental disorders concerned only 35-54-year-old manual workers (among 23\% men and 26\% women).
\end{abstract}

Conclusion The contribution of MSD to the total excess DR among lower socioeconomic groups was large. Prevention of MSD among manual workers would likely reduce socioeconomic differences in DR.

Key terms depression; diagnosis; disability pension; excess disability retirement; mental disorder; mental illness; musculoskeletal disease; musculoskeletal disorder; socioeconomic status.

The large number of disability retirees is a major concern in many developed countries. In Finland 7.5\%, (ie, 203000 of the working-age population) have retired due to work disability. Each year, over 20000 persons retire due to disability. In 2011, the main medical causes for disability retirement (DR) were musculoskeletal diseases (MSD) (35\%) and mental disorders (28\%) (1). The risk of DR increases strongly with age. In particular, DR due to MSD is more common among older employees, while mental disorders are more important causes of DR in the younger age groups (1).

Previous studies have shown that the risk of disability retirement is higher for people with lower socio- economic status (2-7). However, studies examining DR due to $\operatorname{MSD}(2,4,6,8)$, mental disorders $(2,7)$, and cardiovascular diseases (7) have shown that the socioeconomic differences may vary based on the cause of disability. In particular, large socioeconomic differences in DR due to MSD have been found $(2,4,8)$. A Finnish study (2) among municipal employees found a stronger and more consistent socioeconomic gradient in DR due to MSD than mental disorders. The socioeconomic gradient in DR due to mental disorders was relatively weak and non-linear. Another Finnish study (9) among public-sector employees showed that socioeconomic differences in long-term psychiatric work disability

1 Finnish Centre for Pensions, Helsinki, Finland.

2 Hjelt Institute, Department of Public Health, University of Helsinki, Finland.

3 Population Research Unit, Department of Social Research, University of Helsinki, Helsinki, Finland.

Correspondence to: Anu Polvinen, Finnish Centre for Pensions, 00065 Eläketurvakeskus, Finland. [E-mail: anu.polvinen@etk.fi] 
varied widely between certain mental disorders. A strong socioeconomic gradient for DR among Swedish men has been found for alcohol-related diagnoses (10).

The shape and magnitude of socioeconomic differences in disability retirement may vary between the diagnostic causes of DR. However, few studies have compared these variations across various disease groups. Additionally, the diagnoses of disability retirement vary between age groups, and this needs to be taken into account. Our aim was twofold: to examine socioeconomic differences in DR due to several diagnostic causes and find out which diseases contribute most to the overall socioeconomic differences in DR. A further aim was to examine the role that age plays in diagnostic causes regarding the socioeconomic differences in DR.

\section{Methods}

We used longitudinal register data (10\% sample of Finns) from Statistics Finland. Register-based retirement data between the years 1997-2010 were obtained from the Finnish Centre for Pensions. The participants were aged 35-64 years during the follow-up in 1997-2010. The participants belonged to the labor force and were employed or unemployed and did not receive disability or other pension before $1997(\mathrm{~N}=258$ 428). We used an open cohort where new participants were included in the study upon reaching the age of 35 . Follow-up ended at the end of 2010 or due to DR or other retirement, reaching the age for old-age retirement, or death. Age was first categorized into five age groups. However, due to the small number of cases in the younger age groups, the age groups were collapsed into 35-54- and 55-64-year-olds for the analyses using more detailed diagnostic groups. During follow-up, the participants were moved into the older age group when they turned 55 . The division was based on the age differences in the diagnostic causes of DR. In these two age groups, the main causes of DR were different: the younger more often retire due to mental disorders than the older. In older age groups, the proportion of MSD was large. During the follow-up, 14303 men (11\%) and $13188(10 \%)$ women retired due to disability.

\section{Disability retirement due to major diseases}

In Finland, all permanent residents are covered by DR schemes and disability pension is awarded on the basis of a medically confirmed disease leading to a significant reduction in the person's work ability. Our analyses include the first diagnostic cause of DR (1).

The retirement diagnoses were categorized according to the International Classification of diseases (ICD10). We used the following diagnostic groups: MSD
(M00-M99), mental and behavioral disorders (F10F99), cardiovascular diseases (I00-I99), diseases of the nervous system (G00-G99), and neoplasms (C00-D48). Mental and behavioral disorders were further classified into subgroups of psychoactive substance use (F10-F19), schizophrenia (F20-F29) and depressive episodes (F32F33). Musculoskeletal diseases were divided into back diagnoses (M40-M54), arthrosis (M15-M19) and other musculoskeletal diagnoses.

\section{Socioeconomic status}

Socioeconomic status was categorized according to the classification of Statistics Finland (1989) using information primarily from the year 1995 (11). If information on socioeconomic status from that year was missing, we used earlier information on socioeconomic status from 1990, or later information from 2000. Socioeconomic status is based on a person's main type of activity, occupation, occupational status (self-employed/ employee) and branch of industry. The four socioeconomic classes were: upper- and lower-class non-manual employees, manual workers, and self-employed. The self-employed included farmers and small and other employers, entrepreneurs, own-account employees, and other self-employed persons.

\section{Statistical analysis}

The incidence of DR was calculated by dividing the number of DR by the size of the risk group (per 1000 person-years) in each socioeconomic group, and separately for men and women. Age-adjusted Cox models were used to estimate hazard ratios (HR) and 95\% confidence intervals $(95 \% \mathrm{CI})$ for DR due to different diagnoses by socioeconomic status. Analyses were made separately for men and women.

The excess DR in different socioeconomic groups $i$ (reference group $=$ upper-class non-manual employees) and in different diagnostic groups $j$ was calculated using the formula [number of $\left.\mathrm{DR}_{i j}\right]$-[(number of $\left.\mathrm{DR}_{i j}\right) /$ $\left.\mathrm{HR}_{i j}\right]$; where $\mathrm{HR}_{i j}=$ age-adjusted $\mathrm{HR}$ for DR in different socioeconomic groups $i$ and disease groups $j$. The proportional hazards assumptions were tested. Analyses were done using the PHREG procedure in SAS version 9.3 (SAS Institute, Cary, NC, USA).

\section{Results}

The incidence of DR was higher in the older age groups than their younger counterparts (figure 1). In the younger age groups, the main diagnostic cause of DR was mental disorders, while in the older age groups it was MSD. 
Upper-class non-manual employees retired more often due to mental disorders in all age groups. The main diagnostic cause of DR among manual workers, especially in older age groups, was MSD. The overall socioeconomic differences in DR were larger in younger than older age groups. Among the 35-44-year-olds, the incidence of DR among male manual workers was 4-fold compared to upper-class non-manual employees. For 60-64-year-old men, the incidence was 2.6-fold. For women, socioeconomic differences in DR were equally evident, but the magnitude of socioeconomic differences in DR between younger and older age groups differed less than among men. In all age and gender groups, the self-employed had a slightly higher risk for DR than lower-class non-manual employees.

For men, the socioeconomic differences in DR were evident in all diagnostic groups except for depression in the older age group (table 1). The socioeconomic differences were especially large for those who retired due to psychoactive substance use, MSD, or cardiovascular diseases. Among 35-54-year-old men, the HR for DR for manual workers compared to upper-class non-manual employees was 6.3 (95\% CI 4.0-10.5) due to psychoactive substance use, 6.7 (95\% CI 5.4-8.5) due to MSD, and 3.3 (95\% CI 2.5-4.5) due to cardiovascular diseases. In the age group 54-64 years, the socioeconomic differences were weaker than among 35-54-year-olds, except for MSD. Among 54-64-year-old men, the HR for DR for manual workers as compared to upper-class non-manual employees was 6.7 (95\% CI 5.6-8.0) due to MSD, 2.4 (95\% CI 2.0-2.9) due to cardiovascular diseases, and 5.0 (95\% CI 3.1-8.6) due to psychoactive substance use. There were socioeconomic differences in DR due to all mental disorders and depression in the younger age group, but, in the older age group, socioeconomic differences in DR due to all mental disorders or depression were non-existent.

For women, the socioeconomic differences in DR due to all causes were smaller than for men (table 2). Among 35-54-year-old female manual workers as compared to upper-class non-manual employees, the HR for DR was 3.7 (95\% CI 1.9-8.3) due to psychoactive substance use, 5.2 (95\% CI 4.2-6.4) due to MSD, 4.1 (95\% CI 2.6-7.0) due to cardiovascular diseases, and 3.1 (95\% CI 2.3-4.4) due to diseases of the nervous system. Also for women, the socioeconomic differences in DR due to depression or other mental disorders were smaller than due to other diseases. In the age group 55-64 years, the socioeconomic differences were also smaller than in the age group 35-54 years, except for DR due to psychoactive substance use. In the older age group, socioeconomic differences in DR due to depression were inverse or non-existent when due to all mental disorders. Socioeconomic differences in DR due to back diagnoses and arthrosis were broadly similar to socioeconomic dif- ferences in DR due to all MSD (tables 1 and 2).

Among male and female self-employed as compared to upper-class non-manual employees, the socioeconomic differences were largest for DR due to MSD, cardiovascular diseases, and neoplasms for both genders and age-groups (tables 1 and 2).

The contribution of different diseases to the overall socioeconomic differences in DR was calculated for manual workers, lower-class non-manual employees and the self-employed compared to upper-class non-manual employees (table 3). The number of excess DR cases was highest among male manual workers in both age groups. Among male manual workers in the younger age group, MSD accounted for $34 \%$ and mental disorders for $23 \%$ of the total excess. Among male manual workers aged 55-64 years, MSD accounted for over $50 \%$ of the excess while the contribution of mental disorders was negligible. Among male and female lower-class nonmanual employees and the self-employed, the contribution of different diseases to the overall differences was quite similar to manual workers in both age groups. The contribution of MSD to the total excess among female manual workers was $41 \%$ in age group 35-54 years and $76 \%$ in age group 55-64 years. Mental disorders also slightly contributed to the excess DR in the younger age group, but slightly reduced the excess DR cases among the older age group.

\section{Discussion}

This study assessed socioeconomic differences in DR across several diagnostic groups in two age groups among women and men. The socioeconomic differences were largest for DR due to MSD, cardiovascular diseases, and psychoactive substance use. Socioeconomic differences in DR due to depression and any mental disorder were evident in the younger age group, but in the 55-64-year-old group, similar differences could not be found. MSD accounted for a large part of the total excess DR.

The strength of this study is that the data are representative of the Finnish population and information on DR and a broad range of diagnoses is derived from reliable national registers with practically no missing data. Diagnoses are derived from physicians' examinations and are reliable. The data are representative of the Finnish population during the follow-up time (1997-2010). However, as DR schemes vary, the results cannot be directly generalized to other countries or time periods. Also, socioeconomic status was based on register data of occupations, and these data were unavailable only for very few participants. Explanations for socioeconomic differences in DR due to different diseases could not be 


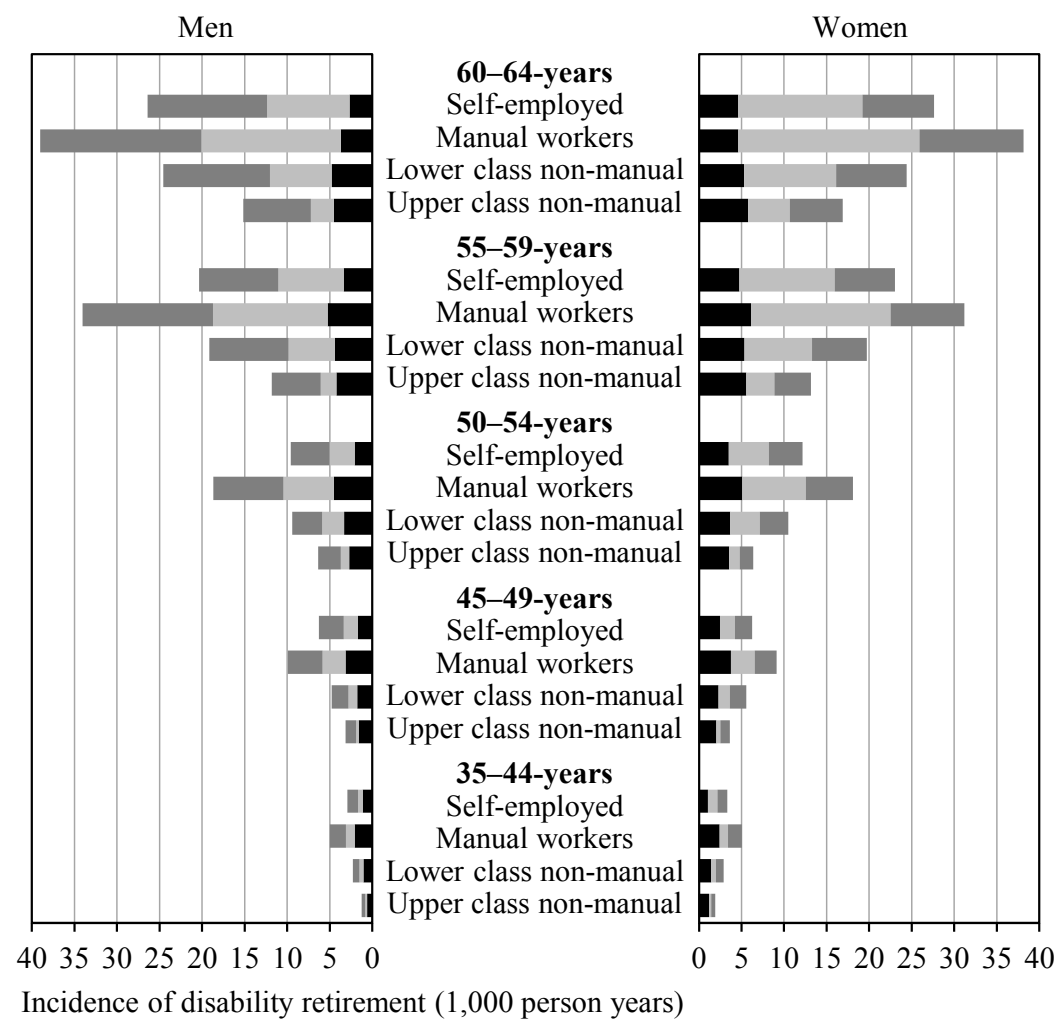

Mental disorders
Musculoskeletal diseases
Other diseases
Figure 1. Incidence of disability retirement due to main diagnostic causes (1000 person years) in five age groups according to socioeconomic status. studied since our data did not include information on potential explanatory factors such as health, working conditions, health behaviors, or living conditions.

Our results are in line with earlier studies examining socioeconomic differences in DR due to musculoskeletal diseases $(2,4,6,12)$ for which large socioeconomic differences have been found. Socioeconomic differences in DR due to arthrosis and back diagnoses were broadly similar to those for all musculoskeletal causes. Previous studies have examined the associations between socioeconomic status and the incidence of MSD, chronic pain, or hospitalization for back disorders among the Finnish population (13-16). Our results are in accordance with these studies, which found that the lower the socioeconomic status, the higher the likelihood of chronic pain, disabling chronic pain or number of hospitalization days.

Socioeconomic differences in DR due to MSD are likely due to more physically strenuous working conditions among manual workers. Various kinds of working conditions have been shown to be risk factors for DR (17-18). In previous studies, a high physical workload, low job control, and chemical and physical exposures at work have provided the largest contributions to socioeconomic differences in DR due to $\operatorname{MSD}(2,4)$. Other factors also associated with socioeconomic differences in DR due to MSD include smoking and body mass index $(2,4)$ as well as diagnosed somatic diseases (4).

Socioeconomic differences in DR due to the diagnosis group of psychoactive substance use were large. Earlier studies have not been able to confirm a clear relationship between socioeconomic status and use of alcohol, the key psychoactive substance. Those in upper socioeconomic classes use alcohol as much as manual workers, but heavy drinking leading to severe problems tends to be more common among lower socioeconomic classes (19-22). Manual workers also run a higher risk of alcohol-related death or hospitalization than upperclass non-manual employees (22). According to earlier studies, problem drinking, heavy average drinking, and frequent drinking predict DR due to mental disorders as well as alcohol-related diagnoses (23-25). Risky use of alcohol and contact with the police, unemployment and other factors associated with low socioeconomic status are strong predictors of DR due to psychoactive substance use (10).

Socioeconomic differences in DR due to cardiovascular diseases were especially large in younger age groups. The mechanisms behind the socioeconomic differences in DR due to cardiovascular diseases are less known. However, previous studies have found large socioeconomic differences in cardiovascular morbidity and mortality. A large number of biological, behavioral, 
Table 1. Socioeconomic differences in disability retirement (DR) due to different diagnoses among men. Hazard ratios (HR) and $95 \%$ confidence intervals $(95 \% \mathrm{Cl})$ by socioeconomic status.

\begin{tabular}{|c|c|c|c|c|c|c|c|c|}
\hline & \multirow{2}{*}{$\begin{array}{c}\begin{array}{c}\text { Upper-class } \\
\text { non-manual }\end{array} \\
\mathrm{HR}\end{array}$} & \multicolumn{2}{|c|}{$\begin{array}{l}\text { Lower-class } \\
\text { non-manual }\end{array}$} & \multicolumn{2}{|c|}{$\begin{array}{l}\text { Manual } \\
\text { workers }\end{array}$} & \multicolumn{2}{|c|}{ Self-employed } & \multirow[t]{2}{*}{$\begin{array}{c}\text { Number } \\
\text { of } D R\end{array}$} \\
\hline & & $\mathrm{HR}$ & $95 \% \mathrm{Cl}$ & $\mathrm{HR}$ & $95 \% \mathrm{Cl}$ & $\mathrm{HR}$ & $95 \% \mathrm{Cl}$ & \\
\hline \multicolumn{9}{|l|}{ 35-54-year-old men } \\
\hline Depression & 1.00 & 1.41 & $1.14-1.75$ & 1.50 & $1.25-1.81$ & 1.08 & $0.84-1.37$ & 969 \\
\hline Psychoactive substance use & 1.00 & 1.50 & $0.83-2.83$ & 6.25 & $3.98-10.53$ & 1.05 & $0.52-2.10$ & 314 \\
\hline Schizophrenia & 1.00 & 0.96 & $0.62-1.47$ & 2.33 & $1.70-3.27$ & 1.01 & $0.62-1.60$ & 352 \\
\hline All mental & 1.00 & 1.25 & $1.07-1.47$ & 2.08 & $1.83-2.37$ & 1.03 & $0.86-1.23$ & 2208 \\
\hline Back diagnoses & 1.00 & 2.62 & $1.88-3.72$ & 6.53 & $4.90-8.93$ & 3.44 & $2.47-4.89$ & 980 \\
\hline Arthrosis & 1.00 & 3.53 & $2.02-6.59$ & 7.61 & $4.66-13.53$ & 3.40 & $1.91-6.40$ & 357 \\
\hline All musculoskeletal & 1.00 & 2.75 & $2.14-3.59$ & 6.69 & $5.36-8.47$ & 3.54 & $2.76-4.61$ & 1734 \\
\hline Cardiovascular & 1.00 & 1.71 & $1.22-2.42$ & 3.31 & $2.51-4.47$ & 2.28 & $1.64-3.21$ & 639 \\
\hline Neoplasms & 1.00 & 1.03 & $0.67-1.59$ & 2.02 & $1.47-2.87$ & 1.78 & $1.20-2.66$ & 337 \\
\hline Nervous system & 1.00 & 1.57 & $1.12-2.21$ & 3.32 & $2.54-4.44$ & 1.15 & $0.78-1.68$ & 622 \\
\hline All diagnoses & 1.00 & 1.54 & $1.39-1.71$ & 3.21 & $2.95-3.50$ & 1.74 & $1.57-1.94$ & 6778 \\
\hline \multicolumn{9}{|l|}{ 55-64-year-old men } \\
\hline Depression & 1.00 & 1.17 & $0.94-1.45$ & 0.88 & $0.73-1.07$ & 0.74 & $0.58-0.94$ & 716 \\
\hline Psychoactive substance use & 1.00 & 1.73 & $0.93-3.29$ & 4.97 & $3.09-8.58$ & 1.23 & $0.63-2.43$ & 215 \\
\hline Schizophrenia & 1.00 & 0.76 & $0.29-1.89$ & 1.82 & $0.98-3.67$ & 0.55 & $0.18-1.46$ & 63 \\
\hline All mental & 1.00 & 1.07 & $0.90-1.27$ & 1.11 & $0.97-1.29$ & 0.72 & $0.59-0.87$ & 1280 \\
\hline Back diagnoses & 1.00 & 2.70 & $2.04-3.60$ & 6.47 & $5.11-8.34$ & 3.76 & $2.89-4.95$ & 1303 \\
\hline Arthrosis & 1.00 & 3.48 & $2.44-5.08$ & 6.62 & $4.84-9.35$ & 4.33 & $3.08-6.27$ & 776 \\
\hline All musculoskeletal & 1.00 & 2.84 & $2.33-3.47$ & 6.69 & $5.64-7.99$ & 3.87 & $3.21-4.71$ & 2662 \\
\hline Cardiovascular & 1.00 & 1.63 & $1.32-2.01$ & 2.38 & $2.01-2.85$ & 1.75 & $1.44-2.15$ & 1302 \\
\hline Neoplasms & 1.00 & 1.64 & $1.19-2.29$ & 1.68 & $1.27-2.26$ & 1.63 & $1.18-2.27$ & 428 \\
\hline Nervous system & 1.00 & 0.96 & $0.70-1.32$ & 2.02 & $1.60-2.57$ & 1.09 & $0.80-1.48$ & 558 \\
\hline All diagnoses & 1.00 & 1.63 & $1.49-1.79$ & 2.79 & $2.56-2.97$ & 1.73 & $1.58-1.89$ & 7525 \\
\hline
\end{tabular}

Table 2. Socioeconomic differences in disability retirement (DR) due to different diagnoses among women. Hazard ratios (HR) and $95 \%$ confidence intervals $(95 \% \mathrm{Cl})$ by sosioeconomic status.

\begin{tabular}{|c|c|c|c|c|c|c|c|c|}
\hline & \multirow{2}{*}{$\begin{array}{c}\text { Upper-class } \\
\text { non-manual } \\
\text { HR }\end{array}$} & \multicolumn{2}{|c|}{$\begin{array}{l}\text { Lower-class } \\
\text { non-manual }\end{array}$} & \multicolumn{2}{|c|}{$\begin{array}{l}\text { Manual } \\
\text { workers }\end{array}$} & \multicolumn{2}{|c|}{ Self-employed } & \multirow[t]{2}{*}{$\begin{array}{c}\text { Number } \\
\text { of DR }\end{array}$} \\
\hline & & $\mathrm{HR}$ & $95 \% \mathrm{Cl}$ & $\mathrm{HR}$ & $95 \% \mathrm{Cl}$ & $\mathrm{HR}$ & $95 \% \mathrm{Cl}$ & \\
\hline \multicolumn{9}{|l|}{ 35-54-year-old women } \\
\hline Depression & 1.00 & 1.08 & $0.92-1.26$ & 1.46 & $1.24-1.72$ & 1.07 & $0.86-1.34$ & 1406 \\
\hline Psychoactive substance use & 1.00 & 1.15 & $0.55-2.64$ & 3.74 & $1.89-8.32$ & 0.33 & $0.04-1.46$ & 82 \\
\hline Schizophrenia & 1.00 & 1.07 & $0.76-1.53$ & 2.38 & $1.71-3.39$ & 1.27 & $0.77-2.06$ & 330 \\
\hline All mental & 1.00 & 1.13 & $1.00-1.27$ & 1.75 & $1.55-1.98$ & 1.06 & $0.89-1.27$ & 2473 \\
\hline Back diagnoses & 1.00 & 2.40 & $1.80-3.27$ & 4.27 & $3.21-5.82$ & 3.20 & $2.27-4.56$ & 787 \\
\hline Arthrosis & 1.00 & 2.57 & $1.62-4.21$ & 7.50 & $4.80-12.49$ & 4.26 & $2.52-7.50$ & 411 \\
\hline All musculoskeletal & 1.00 & 2.44 & $1.99-3.03$ & 5.16 & $4.22-6.38$ & 3.54 & $2.80-4.52$ & 1764 \\
\hline Cardiovascular & 1.00 & 2.07 & $1.28-3.55$ & 4.11 & $2.55-7.04$ & 2.29 & $1.22-4.35$ & 243 \\
\hline Neoplasms & 1.00 & 1.70 & $1.27-2.32$ & 1.74 & $1.27-2.41$ & 2.47 & $1.73-3.55$ & 496 \\
\hline Nervous system & 1.00 & 1.92 & $1.41-2.70$ & 3.13 & $2.27-4.39$ & 1.41 & $0.88-2.24$ & 489 \\
\hline All diagnoses & 1.00 & 1.56 & $1.43-1.71$ & 2.68 & $2.45-2.93$ & 1.80 & $1.60-2.01$ & 6144 \\
\hline \multicolumn{9}{|l|}{ 55-64-year-old women } \\
\hline Depression & 1.00 & 0.90 & $0.76-1.06$ & 0.86 & $0.72-1.03$ & 0.76 & $0.59-0.97$ & 1083 \\
\hline Psychoactive substance use & 1.00 & 2.65 & $0.98-9.86$ & 5.09 & $1.92-18.79$ & 1.14 & $0.19-5.90$ & 60 \\
\hline Schizophrenia & 1.00 & 1.10 & $0.59-2.16$ & 1.65 & $0.88-3.26$ & 1.67 & $0.77-3.66$ & 98 \\
\hline All mental & 1.00 & 0.94 & $0.82-1.09$ & 0.98 & $0.85-1.14$ & 0.80 & $0.66-0.98$ & 1661 \\
\hline Back diagnoses & 1.00 & 2.46 & $1.96-3.14$ & 4.42 & $3.52-5.63$ & 2.68 & $2.03-3.55$ & 1343 \\
\hline Arthrosis & 1.00 & 2.19 & $1.69-2.89$ & 4.99 & $3.88-6.57$ & 3.86 & $2.89-5.21$ & 1126 \\
\hline All musculoskeletal & 1.00 & 2.37 & $2.03-2.78$ & 4.75 & $4.08-5.56$ & 3.28 & $2.75-3.92$ & 3206 \\
\hline Cardiovascular & 1.00 & 1.35 & $1.00-1.86$ & 1.79 & $1.31-2.47$ & 1.55 & $1.03-2.24$ & 458 \\
\hline Neoplasms & 1.00 & 1.58 & $1.18-2.15$ & 2.02 & $1.50-2.76$ & 1.52 & $1.04-2.23$ & 521 \\
\hline Nervous system & 1.00 & 1.29 & $0.92-1.85$ & 1.66 & $1.17-2.39$ & 1.18 & $0.73-1.87$ & 335 \\
\hline All diagnoses & 1.00 & 1.48 & $1.36-1.61$ & 2.29 & $2.11-2.49$ & 1.68 & $1.52-1.87$ & 7044 \\
\hline
\end{tabular}


Table 3. Contribution of different diseases to the overall socioeconomic differences in disability retirement. [Excess disability retirement $t_{\mathrm{ij}}=\left[\right.$ number of disability retirement $\left._{\mathrm{ij}}\right]-\left[\left(\right.\right.$ number of disability retirement $\left.\left.\mathrm{i}_{\mathrm{ij}}\right) / \mathrm{HR}_{\mathrm{ij}}\right]$ where $\mathrm{HR}_{\mathrm{ij}}=$ age-adjusted hazard ratio for disability retirement in disease group $\mathrm{j}$ and socioeconomic group i (ref=upper-class non-manual)]

\begin{tabular}{|c|c|c|c|c|c|c|}
\hline \multirow[t]{2}{*}{ Diagnosis } & \multicolumn{3}{|c|}{$35-54$ years } & \multicolumn{3}{|c|}{ 55-64 years } \\
\hline & $\begin{array}{l}\text { Lower-class non- } \\
\text { manual } \\
(\%)\end{array}$ & $\begin{array}{l}\text { Manual } \\
\text { workers } \\
(\%)\end{array}$ & $\begin{array}{c}\text { Self-employed } \\
(\%)\end{array}$ & $\begin{array}{l}\text { Lower-class non- } \\
\text { manual } \\
(\%)\end{array}$ & $\begin{array}{c}\text { Manual } \\
\text { workers } \\
(\%)\end{array}$ & $\begin{array}{c}\text { Self-employed } \\
(\%)\end{array}$ \\
\hline \multicolumn{7}{|l|}{ Men } \\
\hline Mental & 22 & 23 & 2 & 4 & 2 & -13 \\
\hline Musculoskeletal & 43 & 34 & 46 & 48 & 54 & 65 \\
\hline Cardiovascular & 11 & 9 & 16 & 19 & 15 & 20 \\
\hline Neoplasms & 0 & 3 & 7 & 8 & 3 & 7 \\
\hline Nervous system & 10 & 10 & 2 & -1 & 6 & 1 \\
\hline Other & 14 & 21 & 27 & 22 & 20 & 20 \\
\hline All & 100 & 100 & 100 & 100 & 100 & 100 \\
\hline Number of excess & 321 & 3071 & 344 & 441 & 2762 & 529 \\
\hline \multicolumn{7}{|l|}{ Women } \\
\hline Mental & 13 & 26 & 4 & -9 & -1 & -12 \\
\hline Musculoskeletal & 42 & 41 & 53 & 78 & 76 & 87 \\
\hline Cardiovascular & 5 & 5 & 5 & 5 & 5 & 6 \\
\hline Neoplasms & 11 & 4 & 15 & 10 & 6 & 6 \\
\hline Nervous system & 11 & 9 & 3 & 4 & 3 & 2 \\
\hline Other & 18 & 15 & 20 & 12 & 11 & 11 \\
\hline All & 100 & 100 & 100 & 100 & 100 & 100 \\
\hline Number of excess & 919 & 1507 & 253 & 914 & 1567 & 303 \\
\hline
\end{tabular}

psychological, and social factors contribute to the association between socioeconomic status and mortality from cardiovascular diseases (19, 26-29). For example, diet, smoking, alcohol consumption, physical activity, depression, hopelessness, and marital status have contributed to socioeconomic inequalities in cardiovascular diseases, as have many biological risk factors such as cholesterol, hemoglobin, and body mass index $(19,29)$. Adulthood risk factors have been shown to have a more important role in the explanation of socioeconomic differences in mortality from cardiovascular diseases than childhood socioeconomic circumstances (26). Factors explaining socioeconomic differences in disability retirement due to cardiovascular causes may be similar to those explaining socioeconomic differences in cardiovascular mortality.

Our study shows that there are socioeconomic differences in DR also due to mental disorders, but these differences vary by diagnosis and age. A tendency towards an inverse socioeconomic gradient in disability retirement due to depression among 55-64-years old was suggested. Physically strenuous work and musculoskeletal problems appear to be a common combination that leads older manual workers into DR. Among upper socioeconomic groups, work is less physically strenuous and musculoskeletal problems lead less often to DR, leaving more room for mental disorders as the main diagnostic cause for work disability.

Our findings are in line with previous findings on socioeconomic differences in DR in different age groups. Socioeconomic differences in DR have been found to be larger among younger than older disability retirees (30). Smaller socioeconomic differences in older age groups may be a consequence of the lower socioeconomic status of people having retired due to disability at a younger age. Additionally, poor health at younger ages may lead to a lower socioeconomic status. We examined two age groups of approximately the same size: $35-54-$ and 55-64-year-olds. The DR diagnoses were different in these two age groups, with younger people having mental disorders and older people MSD as their main diagnosis more frequently. We also examined socioeconomic differences in DR due to different diseases in different age groups, but the results were broadly similar to those for two age groups (results not shown).

The contribution of MSD to the total excess DR was large. The proportion of these diseases of the total overall socioeconomic differences was largest for both genders and especially large among older disability retirees. This is likely a result of the large number of DR as well as the large socioeconomic differences in DR due to MSD in both age groups and genders.

\section{Concluding remarks}

Our study found large but varying socioeconomic differences in DR due to different diagnoses and ages, among women and men. The largest differences were found in DR due to MSD, cardiovascular diseases, and psychoactive substance use. Socioeconomic differences in DR due to MSD were relatively large in both age groups, and for both men and women. The contribution of MSD 
to the total excess in DR among manual compared to non-manual employees in the older age group was over $50 \%$ for men and $75 \%$ for women.

Preventing MSD among manual workers would likely reduce socioeconomic differences in DR. Further studies are needed to examine, in detail, the risk factors for socioeconomic differences in DR due to different diseases.

\section{References}

1. The Finnish Centre for Pensions and the Social Insurance Institution of Finland. Statistical yearbook of pensioners in Finland 2011. Official statistics of Finland. Helsinki: Social protection; 2012.

2. Leinonen $\mathrm{T}$, Pietiläinen $\mathrm{O}$, Laaksonen $\mathrm{M}$, Rahkonen $\mathrm{O}$, Lahelma E, Martikainen P. Occupational social class and disability retirement among municipal employees - the contribution of health behaviors and working conditions. Scand J Work Environ Health. 2011;37:464-72. http://dx.doi. org/10.5271/sjweh.3182.

3. Leinonen T, Martikainen P, Lahelma E. Interrelationships between education, occupational social class, and income as determinants of disability retirement. Scand J Public Health. 2012;40:157-66. http://dx.doi.org/10.1177/1403494811435492.

4. Polvinen A, Gould R, Lahelma E, Martikainen P. Socioeconomic differences in disability retirement in Finland: the contribution of ill-health, health behaviors and working conditions. Scand J Public Health. 2013;41:470-478. http:// dx.doi.org/10.1177/1403494813482400.

5. Krokstad S, Johansen R, Westin S. Social determinants of disability pension: a 10-year follow-up of 62000 people in a Norwegian county population. Int J Epidemiol. 2002;31:118391. http://dx.doi.org/10.1093/ije/31.6.1183.

6. Bruusgaard D, Smeby L, Claussen B. Education and disability pension: a stronger association than previously found. Scand J Public Health. 2010;38:686-90. http://dx.doi. org/10.1177/1403494810378916.

7. Månsson N-O, Råstam L, Eriksson K-R, Israelsson B. Socioeconomic inequalities and disability pension in middleaged men. Int J Epidemiol. 1998;27:1019-25. http://dx.doi. org/10.1093/ije/27.6.1019.

8. Ropponen A, Silventoinen K, Svedberg P, Alexanderson K, Koskenvuo K, Huunan-Seppälä A, et al. Health-related risk factors for disability pensions due to musculoskeletal diagnoses: a 30-year Finnish twin cohort study. Scand J Public Health. 2011;39:839-48. http://dx.doi. org/10.1177/1403494811418283.

9. Virtanen M, Kawachi I, Oksanen T, Salo P, Tuisku K, PulkkiRåback L, et al. Socio-economic differences in long-term psychiatric work disability: prospective cohort study of onset, recovery and recurrence. Occup Environ Med. 2011;68:791-8. http://dx.doi.org/10.1136/oem.2010.061101.
10. Upmark M, Lundberg I, Sadigh J, Bigert C. Conditions during childhood and adolescence as explanations of social class differences in disability pension among young men. Scand J Public Health. 2001;29:96-103. http://dx.doi.org/10.1177/14 034948010290020601.

11. Statistics Finland. Classification of socioeconomic groups 1989. Statistics Finland. [Accessed 17 Jan 2013). Available from: http://www.tilastokeskus.fi/meta/luokitukset/ sosioekon_asema/001-1989/index_en.html.

12. Pietikäinen S, Silventoinen K, Svedberg P, Alexanderson K, Huunan-Seppälä A, Koskenvuo K, et al. Health-related and sociodemographic risk factors for disability pension due to low back disorders. A 30-year prospective Finnish Twin Cohort Study. JOEM. 2011;53:488-96.

13. Kaila-Kangas L, Keskimäki I, Notkola V, Mutanen P, Riihimäki H, Leino-Arjas P. How consistently distributed are the socioeconomic differences in severe back morbidity by age and gender? A population based study of hospitalization among Finnish employees. Occup Environ Med. 2006;63:278 82. http://dx.doi.org/10.1136/oem.2005.021642.

14. Kaila-Kangas L, Kivimäki M, Riihimäki H, Luukkonen R, Kirjonen J, Leino-Arjas P. Psychosocial factors at work as predictors of hospitalization for back disorders. A 28-year follow-up of industrial employees. Spine. 2004;29:1823-30. http://dx.doi.org/10.1097/01.BRS.0000134572.46151.0A.

15. Aittomäki A, Lahelma E, Rahkonen O, Leino-Arjas P, Martikainen P. The contribution of musculoskeletal disorders and physical workload to socioeconomic inequalities in health. Eur J Public Health. 2006;17:145-50. http://dx.doi. org/10.1093/eurpub/ckl121.

16. Saastamoinen P, Leino-Arjas P, Laaksonen M, Lahelma E. Socio-economic differences in the prevalence of acute chronic and disabling chronic pain among ageing employees. Pain. 2005;114:364-71. http://dx.doi.org/10.1016/j.pain.2004.12.033.

17. Kärkkäinen S, Pitkäniemi J, Silventoinen K, Svedberg P, Huunan-Seppälä A, Koskenvuo K, et al. Disability pension due to musculoskeletal diagnoses: importance of work-related factors in a prospective cohort study of Finnish twins. Scand J Work Environ Health. 2013;39:343-50. http://dx.doi. org/10.5271/sjweh.3345.

18. Lahelma E, Laaksonen M, Lallukka T, Martikainen P, Pietiläinen $\mathrm{O}$, Saastamoinen $\mathrm{P}$, et al. Working conditions as risk factors for disability pension: a longitudinal register linkage study. BMC Public Health. 2012;12:309. http://dx.doi. org/10.1186/1471-2458-12-309.

19. Méjan C, Droomers M, van der Schouw Y, Sluijs I, Czernichow $\mathrm{S}$, Grobbee D, et al. The contribution of diet and lifestyle to socioeconomic inequalities in cardiovascular morbidity and mortality. Int J Cardiol. 2013;168:5190-5. http://dx.doi. org/10.1016/j.ijcard.2013.07.188.

20. Richter M, Kuntsche E, de Looze M, Pförtner T. Trends in socioeconomic inequalities in adolescent alcohol us in Germany between 1994 and 2006. Int J Public Health. 2013;58:777-84. http://dx.doi.org/10.1007/s00038-0130486-x. 
21. Mäkelä $\mathrm{P}$, Mustonen $\mathrm{H}$, Tigerstedt $\mathrm{C}$, editors. Suomi juo. Suomalaisten alkoholinkäyttö ja sen muutokset 1968-2008. Terveyden ja hyvinvoinnin laitos [Finland drinks. Alcohol use and its changes among Finns in 1968-2008]. Helsinki: Yliopistopaino; 2010.

22. Mäkelä P, Paljärvi T. Do consequences of given pattern of drinking vary by socioeconomic status? A mortality and hospitalization follow-up for alcohol-related causes of the Finnish Drinking Habits Surveys. J Epidemiol Community Health. 2008;62:728-33. http://dx.doi.org/10.1136/ jech.2007.065672.

23. Salonsalmi A, Laaksonen M, Lahelma E, Rahkonen O. Drinking habits and disability retirement. Addiction. 2012; 107:2128-36. http://dx.doi.org/10.1111/j.13600443.2012.03976.x.

24. Upmark M, Lundberg, Sadigh J, Allebeck P, Bigert C. Psychosocial characteristics in young men as predictors of early disability pension with a psychiatric diagnosis. Soc Psychiatry Psychiatr Epidemiol. 1999;34:533-40. http:// dx.doi.org/10.1007/s001270050172.

25. Sidorchuk A, Hemmingsson T, Romelsjö A, Allebeck P. Alcohol Use in Adolescence and Risk of Disability Pension: A 39 Year Follow-up of a Population-Based Conscription Survey. PLos ONE. 2012;7:e42083. http://dx.doi.org/10.1371/ journal.pone.0042083.

26. Kamphuis C, Turrell G, Giskes K, Mackenbach J, van Lenthe F. Socioeconomic inequalities in cardiovascular mortality and the role of childhood socioeconomic conditions and adulthood risk factors: a prospective cohort study with 17-years of follow up. BMC Public Health. 2012;12:1045-56. http://dx.doi. org/10.1186/1471-2458-12-1045.

27. Stringhini S, Sabia S, Shipley M, Brunner E, Nabi H, Kivimäki M, et al. Association of Socioeconomic Position With Health Behaviors and Mortality. JAMA. 2010;303:1159-66. http:// dx.doi.org/10.1001/jama.2010.297.

28. Huisman M, Kunst A, Bopp M, Borgan J, Borrell C, Costa $\mathrm{G}$, et al. Educational inequalities in cause-specific mortality in middle-aged and older men and women in eight western European populations. The Lancet. 2005;365:493-500.

29. Lynch J, Kaplan G, Cohen R, Tuomilehto J, Salonen J. Do cardiovascular risk factors explain the relation between socioeconomic status, risk of all-cause mortality, cardiovascular mortality, and acute myocardial infarction? Am J Epidemiol. 1996;144:934. http://dx.doi.org/10.1093/ oxfordjournals.aje.a008863.

30. Nilsen S, Ernstsen L, Krokstad S, Westin S. Educational inequalities in disability pensioning- the impact of illness and occupational psychosocial, and behavioral factors: The Nord-Trøndelag Health Study (HUNT). Scand J Public Health. 2012;40:133-41. http:// dx.doi.org/10.1177/1403494811435494.

Received for publication: 29 April 2013 